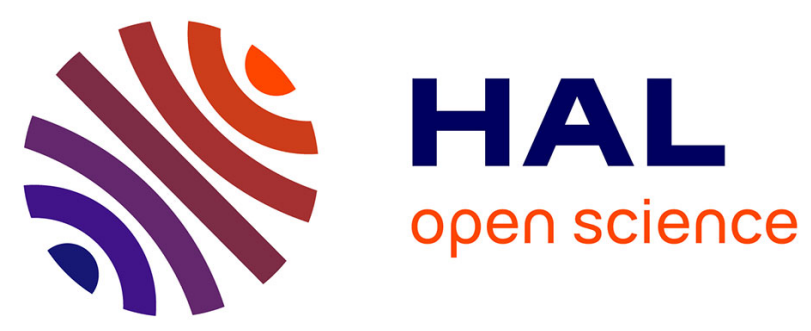

\title{
New method for the growth of single-walled carbon nanotubes from bimetallic nanoalloy catalysts based on Prussian blue analog precursors
}

\author{
A. Castan, S. Forel, L. Catala, I. Florea, F. Fossard, F. Bouanis, A. \\ Andrieux-Ledier, S. Mazerat, T. Mallah, V. Huc, et al.
}

\section{To cite this version:}

A. Castan, S. Forel, L. Catala, I. Florea, F. Fossard, et al.. New method for the growth of singlewalled carbon nanotubes from bimetallic nanoalloy catalysts based on Prussian blue analog precursors. Carbon, 2017, 123, pp.583-592. 10.1016/j.carbon.2017.07.058 . hal-02325471

\section{HAL Id: hal-02325471 \\ https://hal.science/hal-02325471}

Submitted on 22 Oct 2019

HAL is a multi-disciplinary open access archive for the deposit and dissemination of scientific research documents, whether they are published or not. The documents may come from teaching and research institutions in France or abroad, or from public or private research centers.
L'archive ouverte pluridisciplinaire HAL, est destinée au dépôt et à la diffusion de documents scientifiques de niveau recherche, publiés ou non, émanant des établissements d'enseignement et de recherche français ou étrangers, des laboratoires publics ou privés. 
To appear in: Carbon

DOI:

10.1016/j.carbon.2017.07.058

\title{
New method for the growth of single-walled carbon nanotubes from bimetallic nanoalloy catalysts based on Prussian blue analog precursors
}

\author{
A. Castant ${ }^{\mathrm{a},}$ br S. Forel ${ }^{\mathrm{tc}}$, L Catala ${ }^{\mathrm{a}}$, I. Florea ${ }^{\mathrm{c}}$, F. Fossard ${ }^{\mathrm{b}}$, F. Bouanis ${ }^{\mathrm{c}}$, d' A. Andrieux- \\ Ledier $^{\mathrm{b}}$, S. Mazerat ${ }^{\mathrm{a}}$, T. Mallah ${ }^{\mathrm{a}}$, V. Huc ${ }^{\mathrm{a}}$, A. Loiseau ${ }^{\mathrm{b} *}$, C.S. Cojocaru ${ }^{\mathrm{c} *}$ \\ a Institut de Chimie Moléculaire et des Matériaux d'Orsay, Université Paris-Sud, 15 rue Georges Clemenceau, \\ ORSAY, France \\ b Laboratoire d'Etude des Microstructures, CNRS-ONERA, 29 avenue du général Leclerc, CHATILLON, \\ France \\ c Laboratoire de Physique des Interfaces et des Couches Minces, CNRS, Ecole Polytechnique, Université Paris \\ Saclay, 91128, Palaiseau Cedex, France \\ diFSTTAR, COSYS, LISIS, Université Paris Est, Boulevard Newton, CHAMPS-SUR-MARNE, France.
}

t AC. and S. F. contributed equally to this work

\begin{abstract}
Catalyst engineering is a key point for selective growth of single-walled carbon nanotubes (SWCNT) with chemical vapor deposition (CVD). Here, we develop a new general synthesis method able to produce a wide range of homogenous bimetallic catalyst nanoparticles with controlled stoichiometry and sizes. The basics of this catalyst synthesis is to use preformed stoichiometric bimetallic Prussian blue analog (PBA) nanoparticles. Catalyst nanoparticles are then prepared in-situ in a hot filament CVD reactor with subsequent high temperature treatment in reducing atmosphere prior to SWCNT growth. The capabilities of the synthesis route are demonstrated by testing five PBA systems involving various transition metals. Transmission electron microscopy (TEM), scanning TEM and energy dispersive X-ray spectroscopy (STEM-EDX), and in-situ X-ray photoelectron spectroscopy (XPS) measurements are used to finely follow the size and composition of the catalyst at each step of the process. Each system yields small size catalysts with a narrow distribution, which act as efficient catalysts for SWCNT growth with a good yield and small diameter distribution. The versatility of the PBA family paves a new way for a fine tuning of the catalyst properties monitored by the metal involved in the PBA, and for opening routes to more selective SWCNT synthesis.
\end{abstract}

\section{Introduction}

At the forefront in the area of molecular electronics over the past two decades because oftheir unique electronic and optical properties [1], single wall carbon nanotubes (SWCNT) are still facing major challenges for the design of efficient deviees for applications in nanoelectronics

*Annick Loiseau: annick.loiseau@onera.fr, Te1: +33146734453

*Costel Sorin Cojocaru : costel-sorin.cojocaru@polytechnigue.edu, Tel : +33169334356 
[2] and sensors [3]. This is mainly due to the intricate relation between their physical properties and their structure i.e. their chiral angle and diameter. Controlling their structural properties during the growth process is therefore a key point for the progress in this field. Recently, many groups [4] have reported diameter selectivity [5],[6], chiral selectivity [7],[8],[9], and semiconductor [1ü] or metallic [11] enriched SWCNT samples. While sorne studies emphasized on the fine tuning of chemical vapor deposition (CVD) parameters [12] or on a judicious choice of the carbon feedstock[13], other studies focused on the investigation ofthe role ofsize [14], morphology [15], and composition ofcatalyst nanoparticles. For the latter, a strategy employed by sorne groups consisted in using bimetallic catalysts such as CoMo [16],[17], FeRu [18], FeCu [8], CoCu [19], FeCo [20], FePt [21], FeTi [22], FeMn [23], and CoW [24],[25] for the CVD growth of SWCNTs. This bimetallic catalyst approach has led to sorne chiral selectivity, but both the catalyst nature (size, morphology, structure...) and the growth conditions differ drastically from one study to another, precluding any direct comparison and deep understanding of the effect of the bimetallic catalyst on the SWCNT growth process. In order to systematically investigate the effect of the chemical nature of the alloys on the structure of SWCNTs, it is crucial to perform the growth process using different alloy catalyst combinations with comparable sizes and morphologies together with fixed and well-known CVD parameters.

In this study, we present a new and versatile approach to grow SWCNTs by means of a variety of bimetallic catalysts that are obtained in-situ from Prussian blue analog (PBA) precursors. PBAs are bimetallic three-dimensional coordination networks with a face-centered cubic (fee) lattice structure of altemating metal ions linked by cyanide bridges [26] (see Fig.1 for schematic structure).

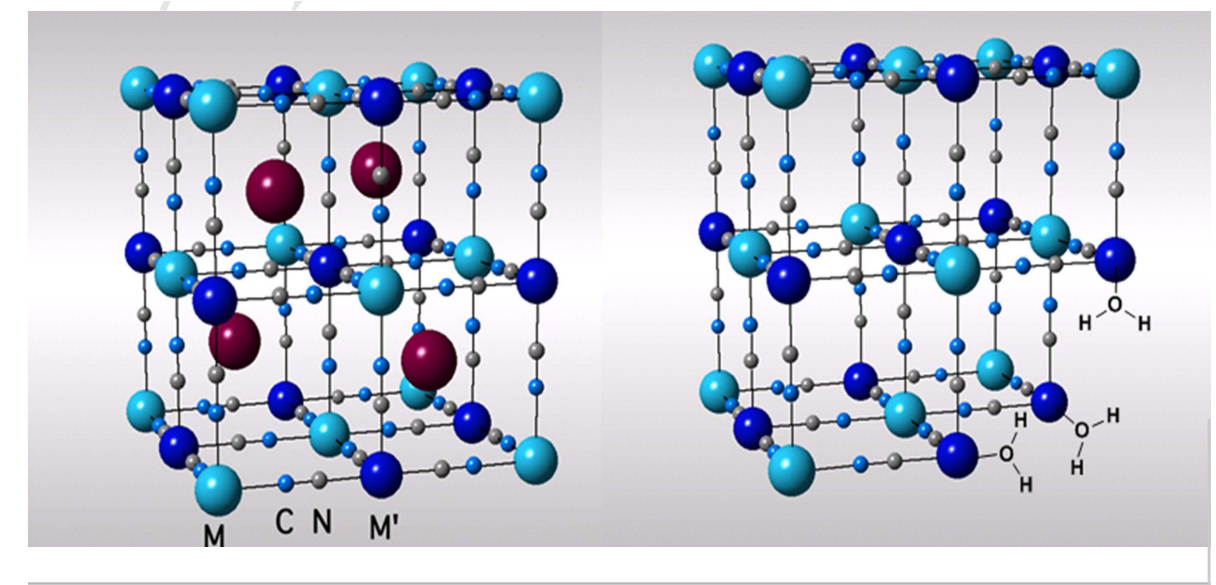

Fig. 1: PBA schematic structure, the two metal ions $M$ and $M^{\prime}$ are linked by coordination bonds to cyanide bridges within vacancy free fee lattice structure (left), and water molecules replacing $M(C N)_{6}$ vacancies thal may be present in the lattice (righi) 
PBA nanoparticles can be synthesized with a narrow size distribution and a welidefined composition, enabling the control of the catalyst size and composition. This study features SWCNT growth from a total offive different bimetaliic PBA precursors. Sorne of them were developed for this purpose. We used the same preparation process for ali bimetaliic systems ensuring that the only varying parameter is the bimetaliic combination. Alloy-like bimetallic catalyst nanoparticles were then obtained from sorne PBA precursors and are used for the growth of SWCNTs with a satisfying yield, and with diameters ranging from $0.7 \mathrm{~nm}$ to $2.6 \mathrm{~nm}$ as characterized by Raman spectroscopy and TEM analyses.

\section{Experimental section}

The global multistep process leading to the growth of SWCNTs [27],[28] from PBA precursors is shown in Fig. 2 Details on the various steps ofthis process are provided in the following paragraphs.

\subsection{PBA nanoparticles synthesis}

For ali the systems considered in this study, the PBA nanoparticles were synthesized using a co-precipitation method previously described by Catala et al. [29],[30]

An aqueous solution containing the potassium hexacyanometallate $\left[\mathrm{M}(\mathrm{CN})_{6} \mathrm{Y}+\right.$ salt and cesium chloride $(\mathrm{CsCl})$ or potassium chloride $(\mathrm{KCl})$, depending on the bimetallic system, was added to an aqueous solution of the hexa-aquo complex $\left[\mathrm{M}^{\prime}\left(\mathrm{H}_{2} \mathrm{O}\right)_{6}\right]^{2+}$.

The as-obtained PBA nanoparticles are stable in water without any stabilizing agent due to their negative charge, which leaves their surface available to coordinate to an organic ligand.

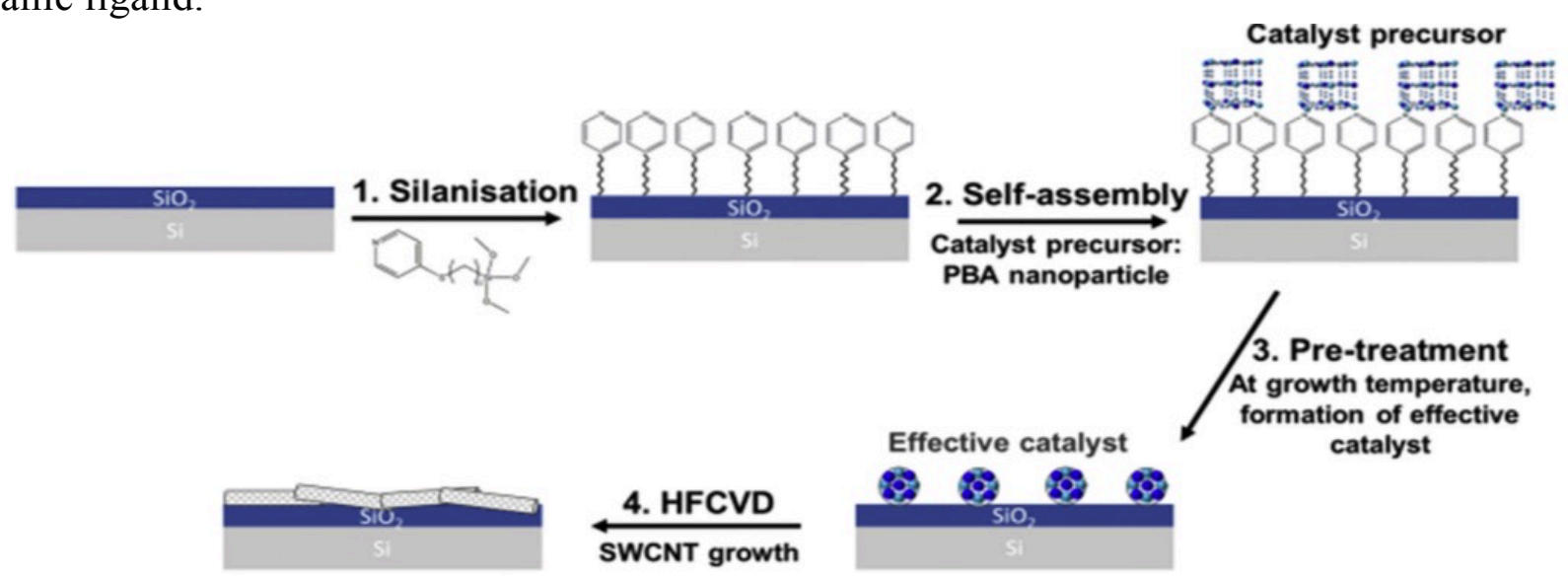

Fig. 2 : Schematie view of the main steps of the SWCNT growth process Fom PBA precursors. A $\mathrm{SiO} / \mathrm{Si}$ wafer is functionalized with an organic ligand for anchoring the PBA nanoparticles with a coordination bond; a reductive pre-treatment yields in the formation of bimetallic catalyst nanoparticles, after which SWCNT growth is performed by d-HFCVD. 
For their chemical and structural characterization, PBA nanoparticles were recovered as powders by adding an excess of calcium chloride salt ( $\mathrm{CaCb}$ ) followed by centrifugation, washing and drying the powder under vacuum.

\subsection{Substrate preparation and functionalization}

All wafers used in this study are $300 \mathrm{~nm}$ thermal $\mathrm{SiO}_{2}$ coated silicon wafers purchased from SiMat. Each sample was cleaned by ultrasonication in dichloromethane $\left(\mathrm{CH}_{2} \mathrm{Cb}\right)$ for 15 minutes, followed by 10 minutes of Ar-0 plasma treatment in order to activate the $\mathrm{SiO}_{2}$ surface. The cleaned $\mathrm{SiO}_{2} / \mathrm{Si}$ wafers were functionalized, according to the synthesis protocol described in [28], with a self-assembled monolayer (SAM) of a silane molecule having a terminal pyridine group able to form a coordination bond with the PBA nanoparticles. The wafers were immersed in a $10^{3} \mathrm{M}$ solution of the silane molecule in distilled toluene $\left(\mathrm{C}_{7} \mathrm{H}_{8}\right)$ for 12 hours. The samples were subsequently rinsed with toluene and dichloromethane followed by annealing at $100{ }^{\circ} \mathrm{C}$ for two hours in ambient air.

In order to graft the PBA nanoparticles, the silanised wafers were immersed in the as-obtained colloidal PBA solution for one hour. The excess of nanoparticles was rinsed off with deionized water, and the wafers were left to dry under air such as to get coated by a single layer ofthe PBA nanoparticles.

\subsection{Catalyst preparation and SWCNT growth}

The catalyst precursor reductive pre-treatment and the SWCNT growth were conducted in a homemade double hot filament chemical vapor deposition (d-HFCVD) reactor, consisting of a cylindrical quartz tube enclosed in an $80 \mathrm{~mm}$ wide tubular heater with approximately $250 \mathrm{~mm}$ uniform heated length.

The reactor, with a base residual pressure of $10^{.6} \mathrm{mbar}$, is connected to two separate inlets for hydrogen and methane respectively. Each of the two gases has a forced flow over a separate tungsten filament $(0.38 \mathrm{~mm}$ diameter $)$, mounted horizontally near the substrate in the CVD chamber and independently electrically driven at variable power (see Fig. S1 presenting a schematic view of the reactor). The first step of the synthesis process is a hot reductive treatment under hydrogen of the PBA particles into bimetallic particles. For that purpose, the wafers coated by the PBA nanoparticles were placed in the cold zone of the CVD chamber, the chamber was pumped to a $10{ }^{6}$ mbar pressure, and the temperature was set to $8000 \mathbf{C}$ in the hot zone. After stabilization of the temperature, $\mathrm{H}_{2}$ was introduced at $100 \mathrm{sccm}$ (standard cubic centimeters per minute) flow rate, and the corresponding filament power of $160 \mathrm{~W}$ 
tumed on. Once the pressure of the chamber was stabilized at 90 mbar, the wafers were moved into the hot zone and maintained in the reductive atmosphere for 5 minutes. This treatment is immediately followed by the SWCNT synthesis, by directly introducing $\mathrm{CH}_{4}$ (without modifying $\mathrm{H}_{2}$ flow rate) at $20 \mathrm{sccm}$ flow rate and for a corresponding hot filament power of $120 \mathrm{~W}$, while the overall pressure was increased to 100 mbar. These growth conditions are maintained during 30 minutes, after which the chamber was pumped and the samples removed from the hot zone.

In order to investigate the step related to the catalyst nanoparticles formation, sorne samples were removed from the chamber after the reductive pre-treatment prior to the SWCNT growth step.

\subsection{Characterization}

\subsubsection{PBA nanoparticles}

The PBA nanoparticles were characterized by transmission infrared spectroscopy, performed on a Perkin Elmer Spectrum 100 spectrometer and by reflexion IR performed on a Brüker VERTEX 70. X-ray powder diffraction (XRPD) analyses were performed on powder deposited on aluminum plate and recorded on a Phillips Panalytical X'Pert Pro MPD powder diffractor at CuKa (1.5404 À) radiation equipped with a fast detector. Transmission electron microscopy imaging was performed using an image corrected FEI TITAN TEM operating at $300 \mathrm{kV}$.

The AFM analysis of the PBA nanoparticles deposited on $\mathrm{SiO}_{2} / \mathrm{Si}$ substrates was performed using di Innova AFM Bruker with NanoDrive v8.02 software. Tapping mode images were acquired using silicon tips from nanosensors (PPP-NCSTR) with a resonance frequency ranging between 76 and $263 \mathrm{kHz}$. Images were processed using WsXM software.

\subsubsection{Catalyst nanoparticles}

The in-situ X-ray photoelectron spectroscopy (XPS) analysis of the reduction of PBA nanoparticles was conducted on a homemade synthesis and characterization platform, Facility for Elaboration of Nanomaterials with in-situ and real time characterization@X (FENIX) designed to study in-situ and in real time, by surface analysis techniques (XPS, ultraviolet photoelectron spectroscopy, Auger electron spectroscopy, low energy electron diffraction, cathodoluminescence), the growth of graphitic materials. Large flows of carbon and hydrogen 
can be locally delivered under the form of confined radicals/molecular beams in ultra-high vacuum to simulate various growth environments (CVD, plasma enhanced CVD, d-HFCVD).

For TEM characterizations, the catalyst nanoparticles issued from the pre-treatment step were transferred onto $\mathrm{Cu}$ grids coated with an amorphous carbon membrane using a procedure detailed below. TEM was performed on the same equipment as for the catalyst precursor nanoparticles, as well as on a Libra 200 MC Zeiss microscope equipped with a Gatan Ultrascan camera operating at $200 \mathrm{kV}$. The scanning TEM and energy dispersive X-ray spectroscopy (STEM-EDX) analysis was performed on a probe corrected FEI TITAN microscope operating at $200 \mathrm{kV}$.

\subsubsection{SWCNTs}

The Raman spectroscopy was performed on a HORIBA LabRam ARAMIS spectrometer, using a x100 objective, with four excitation wavelengths $(473 \mathrm{~nm}, 532 \mathrm{~nm}, 633 \mathrm{~nm}$, and 785 $\mathrm{nm})$. For all samples and at each wavelength, several mappings were carried out, at random locations on the substrate to get the most meaningful statistical analysis. The mappings were clone on a $5011 \mathrm{~m}$ by $5011 \mathrm{~m}$ surface, with a $511 \mathrm{~m}$ step. Scanning electron microscopy (SEM) observations were carried out on HITACHI S 4800 microscope at $1 \mathrm{kV}$ (or $0.5 \mathrm{kV}$ ) and 10 11A TEM images were recorded with the image correctecl FEI TITAN TEM microscope 80 $\mathrm{kV}$ after transferring the SWCNTs on TEM grids.

\subsubsection{Wafer to grid transfer method}

TEM and STEM-EDX inspection of the nanoparticles and/or SWCNTs require their transfer from $\mathrm{SiO}_{2} / \mathrm{Si}$ wafers, used for their formation, onto a TEM grid. For that purpose, we have adapted the conventional poly(methyl-methacrylate) (PMMA) transfer method [31]. First, a thin layer of PMMA (495PMMA A4 purchased from MicroChem) was spin-coated on the wafer at $500 \mathrm{rpm}$ for 90 seconds. This system was dried at ambient temperature for 12 hours. The PMMA film containing the SWCNTs and/or the bimetallic nanoparticles was then lifted off the wafer by etching the $\mathrm{SiO}_{2}$ layer into a sodium hydroxide aqueous solution $(\mathrm{NaOH}, 1$ mol $\mathrm{L}^{\prime 1}$ ) for a few hours. This film was recovered, transferred and rinsed repeatedly in deionized water. A TEM grid was placed under the film, and a maximum of excess water was removed, until the film stuck onto the grid. The system was then slowly ramped up until 120 $0 \mathbf{C}$ on a hot plate and left to dry ovemight. The dried PMMA was then removed with acetone.

In contract to the requirements for deviee fabrication [32], characterization of SWCNTs does not require the PMMA to be completely removed as it can serve as a support for the 
SWCNTs, facilitating their observation. However, the presence of PMMA is a drawback for the characterization of catalyst nanoparticles, being source of contamination, and it is therefore preferable to remove it as much as possible.

\section{Results and discussion}

\subsection{Pre-Catalyst nanoparticles}

PBAs offer a various range of bimetallic (or trimetallic in sorne cases) coordination nanoparticles [33] with a metallic ratio that may vary from 1:1 to 1:0.5 depending on the system. They are used as precursors to obtain, after pyrolysis, different bimetallic nanoparticles with well-defined size and chemical composition. In this study, we use five different bimetallic PBA precursors for SWCNT synthesis of general formula CsNinFem $(\mathrm{CN})_{6}, \quad \operatorname{CsNinCrm}(\mathrm{CN})_{6}, \quad \operatorname{CsNinRun}(\mathrm{CN})_{6}, \quad \operatorname{CsConRun}(\mathrm{CN})_{6}, \quad$ and KFemRun(CN)6. The reader should note that all PBA systems studied here will thereafter be referred to by the two $M$ and $M^{\prime}$ metals of interest (FeRu for the $\mathrm{KFemRun}(\mathrm{CN})_{6}$ system for instance).

For these five systems, aqueous dispersions of individualized particles with slzes below $4 \mathrm{~nm}$ are obtained, that are ideal to generate sub-4 $\mathrm{nm}$ bimetallic particles through the reductive pre-treatment previously described. To the best of our knowledge, a majority of these bimetallic systems have not all been thoroughly investigated as catalysts for SWCNT growth. Sorne of the selected combinations of metals ( $\mathrm{FeNi}$ and $\mathrm{FeRu}$ ) have been shown to catalyze SWCNT growth with efficiency and variable selectivity, and while significant efforts were made to characterize the catalyst nanoparticles in the case of the FeNi system, the nature of the catalyst was not fully investigated for the latter [34]'[18].The other systems studied here have either, to the best of our knowledge, not yet been investigated for the growth of SWCNTs (CoRu and $\mathrm{NiRu}$ ), or only investigated for the growth of multiwall CNTs, like the $\mathrm{NiCr}$ system[35]'[36]. Moreover, the approach we developed also allows for the first time to investigate a series of catalysts produced in identical conditions and in principle, the methodology can be easily extended to a much broader range of bimetallic and even trimetallic systems.

Chemical and structural characterizations were performed on powders of all five PBA systems. The infrared spectra of each compound are displayed in Fig. S2. For each of the PBA compounds, characteristic bands of the cyanide bridged PBAs (2070-2200 
$\mathrm{cm}^{-1}$ ) and solvate water molecule (bending mode of $\mathrm{OH}$ bond between 1400 and 1650 $\mathrm{cm}^{-1}$ ) included in the porous networks were observed. As compared to the corresponding hexacyanometallate $(\mathrm{M}-\mathrm{CN})$ complex, $\mathrm{VeN}$ are found to be blue-shifted in agreement with the bridging of cyanide ligands (M-CN-M'). The non-bridging (NB) cyanides $(\mathrm{M}-\mathrm{CN})$ located at the surface of the nanoparticles can also be observed. Furthermore the fee crystalline structure of the PBA is confirmed through the XRPD patterns shown in Fig. 3. The lattice parameters extracted from XRPD patterns are ranging between 10.29 and $10.56 \mathrm{~A}$ and correspond to expected values for PBA [26].

Details on the lattice constant calculations are provided in Table S1. The Scherrer equation was used to calculate an approximate crystallite size, in terms of a Scherrer domain size, found to be below $7 \mathrm{~nm}$ for each system, confirming the small size of the PBA nanoparticles (see table Fig. 3). It should be noted that for crystallites smaller than $10 \mathrm{~nm}$, a significant error on the domain size is expected.

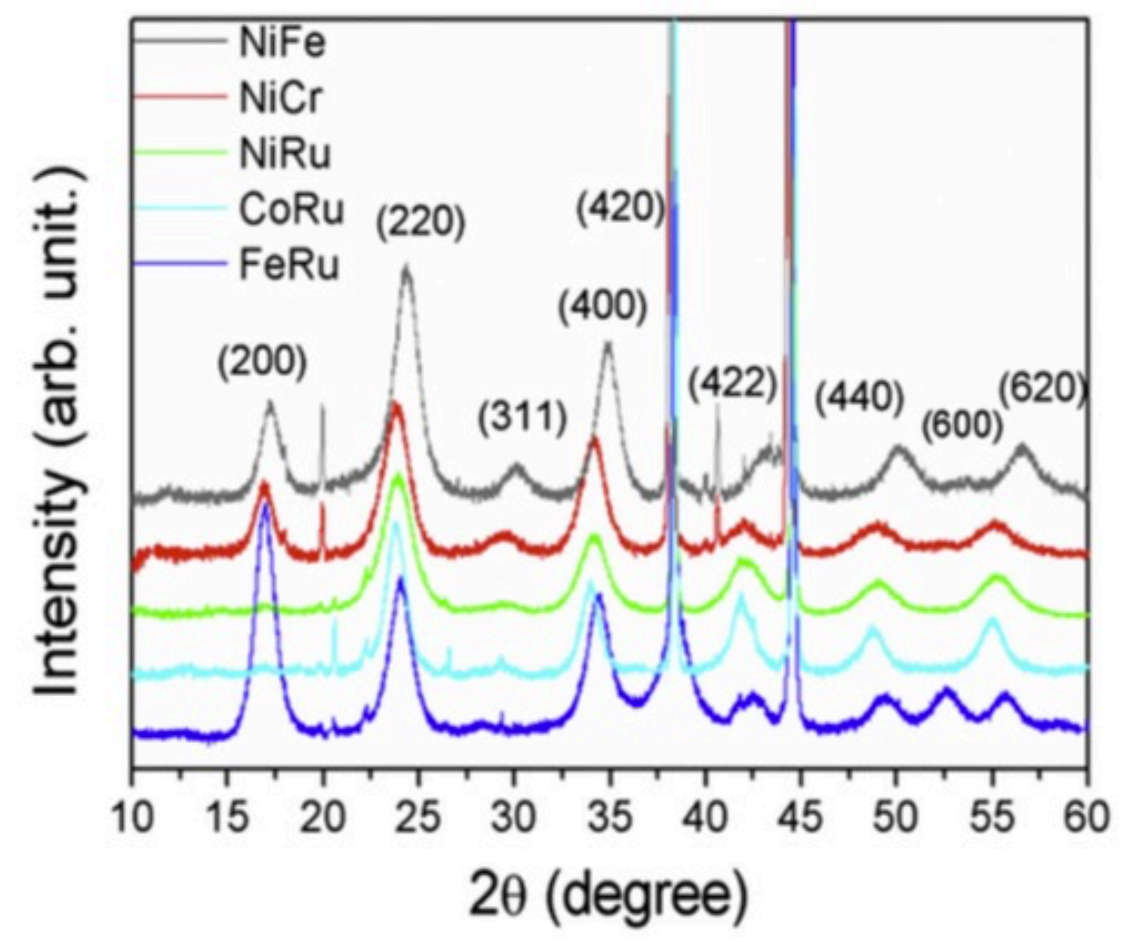

\begin{tabular}{|c|c|c|c|c|c|}
\hline $\begin{array}{c}\text { Precatalyst } \\
\operatorname{AxM}\left[M^{\prime}(C V)_{6}^{6}\right.\end{array}$ & FeRu & CoRu & NiRu & $\mathrm{NiCr}$ & Nife \\
\hline Lattice con tant $(\hat{\mathrm{A}})$ & 10.44 & 10.56 & 10.51 & 10.52 & 10.29 \\
\hline $\begin{array}{c}\text { cherer domain ize } \\
(\mathrm{nm})\end{array}$ & 5.6 & 6. & 4.2 & 4.9 & 5.3 \\
\hline
\end{tabular}

Fig. 3 top: XRPD patterns of PBA powders for all studied systems, bottom: table of structural characteristics of PBA nanoparticles

Chemical composition for the synthetized PBA nanoparticles was derived from SEMEDX analysis and as expected, metallic ratios of approximately 1:1 (+- 0.09) were confirmed (Table S2 and Fig. S3). 
TEM studies confirm the pre-catalyst (PBA) narrow and small size distribution. For all pre-catalyst PBA nanoparticles the average size is found to lie between 2 and $4 \mathrm{~nm}$, from statistical analyses made over roughly 200 particles for each system (see table in Fig. 6). Typical TEM images of the nanoparticles and their corresponding statistical size distributions are shown in Fig. 4.

As explained in the experimental section, the PBA nanoparticles are deposited on $\mathrm{SiO}_{2} / \mathrm{Si}$ wafers after the formation of an anchoring SAM on the surface. In order to ensure that the nanoparticles are grafted on the surface, and to evaluate the quality of
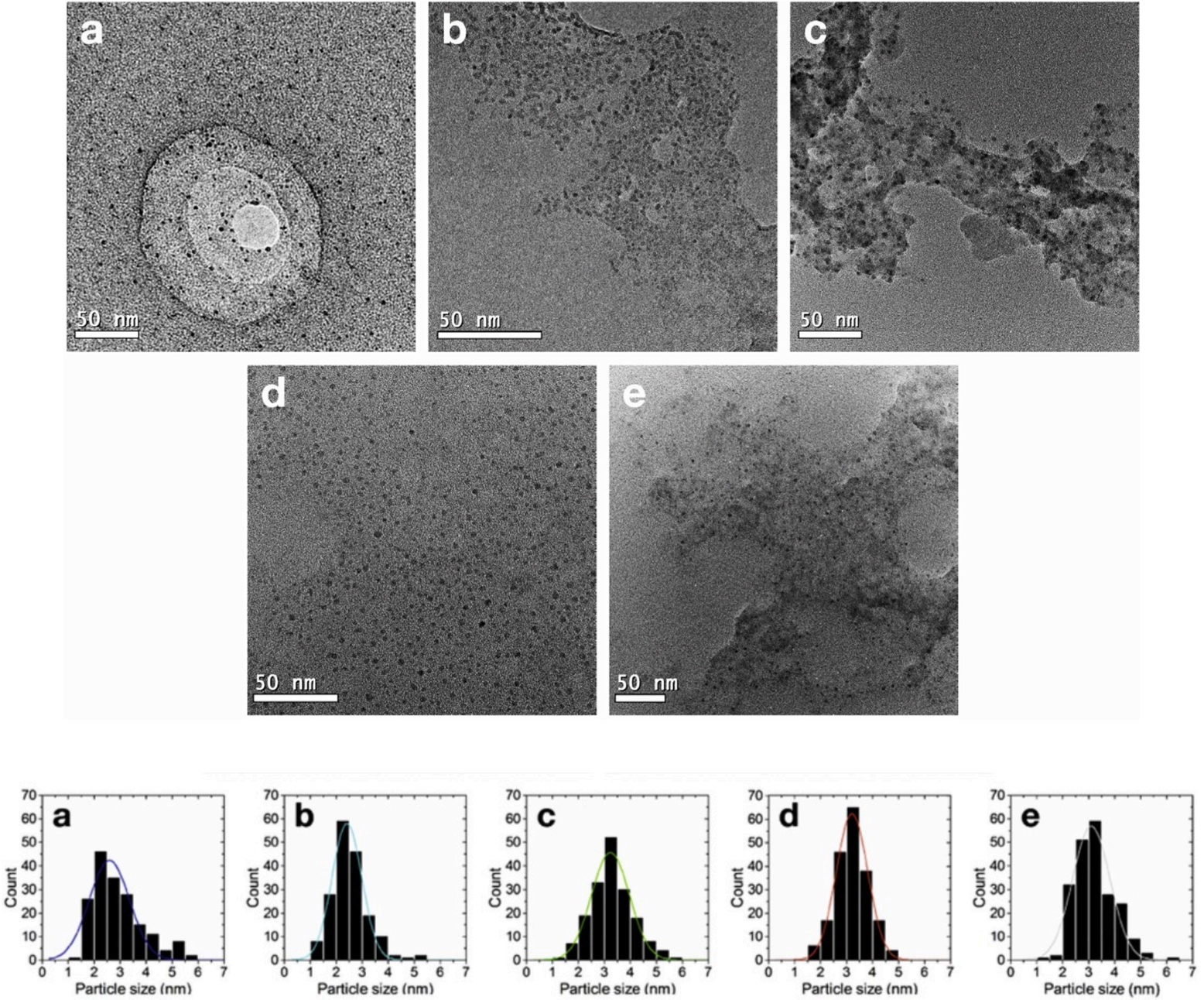

Fig. 4 typical TEM images, and bottom: size distributions of a) FeRu PBA, b) CoRu PBA c) NiRu PBA, d) $\mathrm{NiCr}$ PBA, ande) NiFe PBA nanoparticles 
the deposition, AFM measurements were conducted for all PBA systems. Examples of

AFM images of a $2 \times 2 \mathrm{f} .1 \mathrm{~m}^{2}$ surface are presented in Fig. S4. A dense and homogeneous layer of nanoparticles with heights corresponding to the sizes measured in TEM can be observed.

\subsection{Catalyst nanoparticles}

The reductive pre-treatment of the catalyst precursor serves two purposes: first for degrading the organic SAM, and second for reducing the PBA nanoparticles into metallic catalyst nanoparticles. In order to study the reduction process, an in-situ XPS analysis of the PBA nanoparticles was conducted in the case of the FeRu system using the FENIX facility. XPS analysis was carried out in-situ, before and after reduction of FeRu PBA nanoparticles. Spectra were recorded before the reduction of the PBA nanoparticles grafted on the silanised wafer.

Then the sample was exposed to $\mathrm{H}_{2}$ for $5 \mathrm{~min}$ at $800{ }^{\circ} \mathrm{C}$, and another XPS spectrum was measured after rapid cooling of the samples (approximately $1000 \mathbf{C}$ per minute). It is worth mentioning that the FENIX facility has been designed to realize characterization in a quasi-macroscale as both the synthesis and the analysis areas are in the range of several tens of $\mathrm{nm}^{2}$ and up to $1.5 \mathrm{~cm}^{2}$ in contrast to the characterizations presented in the next sections, which are done at a much lower scale.

As shown in the XPS spectra of Fig. 5, before the reductive pre-treatment (blue line), we observe the characteristic edges of Fem (Fem 2p $3 ; 2$ peak at $710.0 \mathrm{eV}$, and Fem 2pl12 peak at $723.6 \mathrm{eV}$ binding energy), Rurr (Run $3 \mathrm{~d}_{512}$ and $3 \mathrm{~d}_{312}$ peaks at $280.9 \mathrm{eV}$, and $284.9 \mathrm{eV}$, respectively), and nitrogen present in both the cyanide bridges of PBA nanoparticles $(397.9 \mathrm{eV})$ and pyridine groups from the underlying organic SAM (402.1
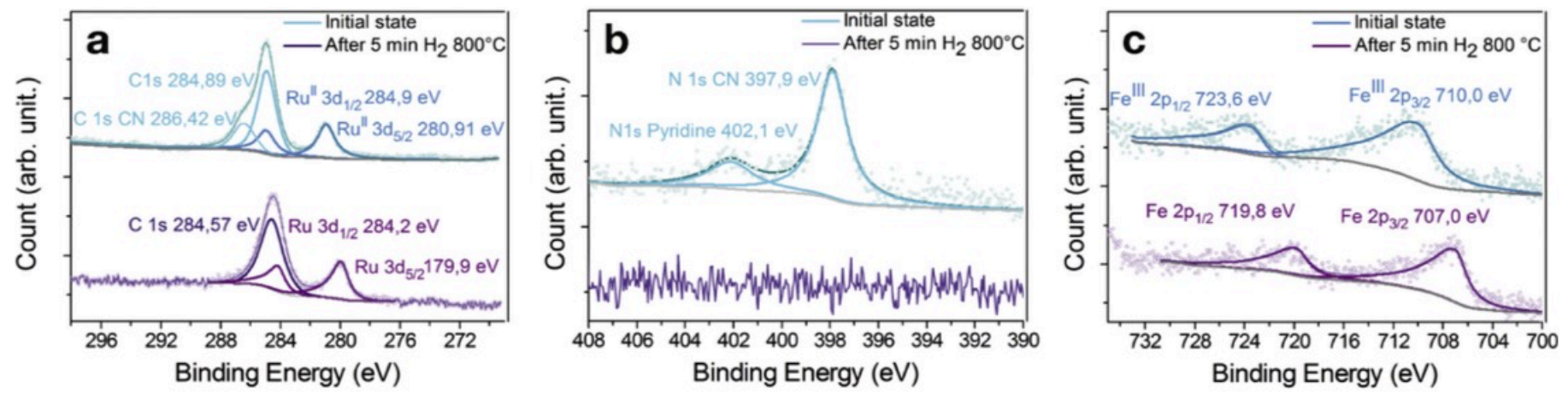

Fig. 5 XPS spectra obtained from in-situ analysis before (blue) and after (purple) reductive pre-treatment at $800^{\circ} \mathrm{C}$ under $\mathrm{H}_{2}$ atmosphere: a) carbon and ruthenium edges, b) nitrogen edge c) iron edge 
eV).[37] A separate study of a non-silanised $\mathrm{SiO}_{2} / \mathrm{Si}$ wafer on which the aqueous solution containing the FeRu PBA nanoparticles was dropped, confirms that the peak at $397.9 \mathrm{eV}$ at the Nls edge can be attributed to the nitrogen atoms belonging to the cyanide bridges of the PBA structure. After the reductive pre-treatment (purple line), we note the disappearance of the characteristic peaks at the N1s edge, indicating the evolution of the PBA structure to a new one free of cyanides and of the SAM. A significant shift and transformation of the characteristic Fe $2 p$ (from $710.0 \mathrm{eV}$ to 707.0 $\mathrm{eV}$ for the $\mathrm{Fe} 2 \mathrm{p}_{3 ; 2}$ peak, and from $723.6 \mathrm{eV}$ to $719.8 \mathrm{eV}$ for the $\mathrm{Fe} 2 \mathrm{pu}_{2}$ peak) and $\mathrm{Ru}$ 3d (from $280.9 \mathrm{eV}$ to $179.9 \mathrm{eV}$ for the $\mathrm{Ru} 3 \mathrm{dll} 2$ peak, and from $284.9 \mathrm{eV}$ to $284.2 \mathrm{eV}$

for the $\mathrm{Ru} 3 \mathrm{~d}_{5 ; 2}$ peak) edges, respectively indicate the reduction of Fem and Run to the metallic state. Around $40 \%$ of carbon has been removed during the reductive pretreatment. The degradation of the PBA was confirmed by the disappearance of the carbon edge peak $(386.4 \mathrm{eV})$ belonging to cyanide. The small shift of the carbon edge belonging to the SAM (from $384.9 \mathrm{eV}$ to $384.6 \mathrm{eV}$ ) also indicates the degradation of the SAM. The pretreatment does not seem to fully remove the carbon originating from the SAM, as a residual peak is observed after pretreatment. However, no peaks indicative of the formation of carbides are observable, suggesting that the remaining carbon is not inside the catalyst nanoparticles. Also, no peak indicati ve of the presence of $\mathrm{K}$ or $\mathrm{Cl}$ (used in the synthesis of the FeRu PBA nanoparticles) around $292.9 \mathrm{eV}$ and $199 \mathrm{eV}$ respectively is detected (see Fig.5a and Fig S5). This XPS study confirms the reduction of the FeRu PBAs, and the destruction of the SAM at the macroscopic scale. Next, the TEM study of the bimetallic alloy partieles provides more information on the catalysts at the microscopie scale.

The size distributions of the catalyst nanoparticles were determined by TEM imaging after their transfer onto carbon membranes. Fig. 6 shows an example of an image of the $\mathrm{NiRu}$ catalyst particles, and the size distributions for all the systems. These distributions clearly emphasize that formation of nanoparticles with a controlled size is achieved with our method: for all systems, the diameter distribution is centered between 1.5 and $2.3 \mathrm{~nm}$, with a maximum standard deviation of $0.8 \mathrm{~nm}$. As shown in the table in Fig. 6, the observed mean nanocluster sizes for the bimetallic catalysts representa systematic decrease of about 30\% to 50\% (depending on the system) of the average size of the initial PBA pre-catalyst nanoparticles ranging from 2.4 to $3.2 \mathrm{~nm}$. Particle size $(\mathrm{nm})$
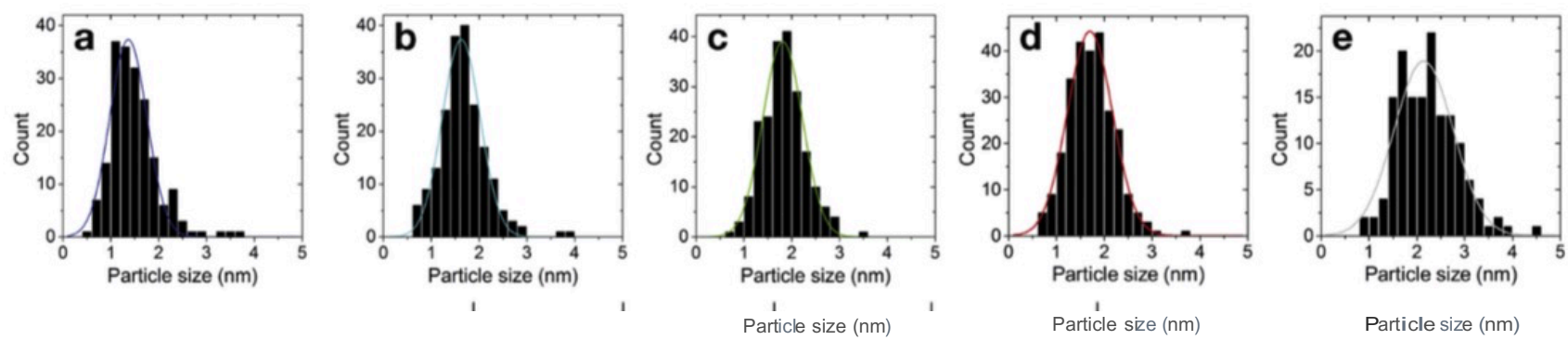

\begin{tabular}{c|c|c|c|c|c} 
Bimetallic system & FeRu & CoRu & NiRu & NiCr & NiFe \\
\hline $\begin{array}{c}\text { Precatalyst } \\
\text { AxM'[M(CN) } 6\end{array}$ & $2.9+/-1.0$ & $2.5+1-0.7$ & $3.3+/-0.9$ & $3.2+/-0.6$ & $3.2+/-0.8$ \\
\hline $\begin{array}{c}\text { Effective Catalyst } \\
\text { MM' }\end{array}$ & $1.5+/-0.5$ & $1.7+/-0.5$ & $1.8+/-0.4$ & $1.7+/-0.6$ & $2.3+/-0.8$
\end{tabular}




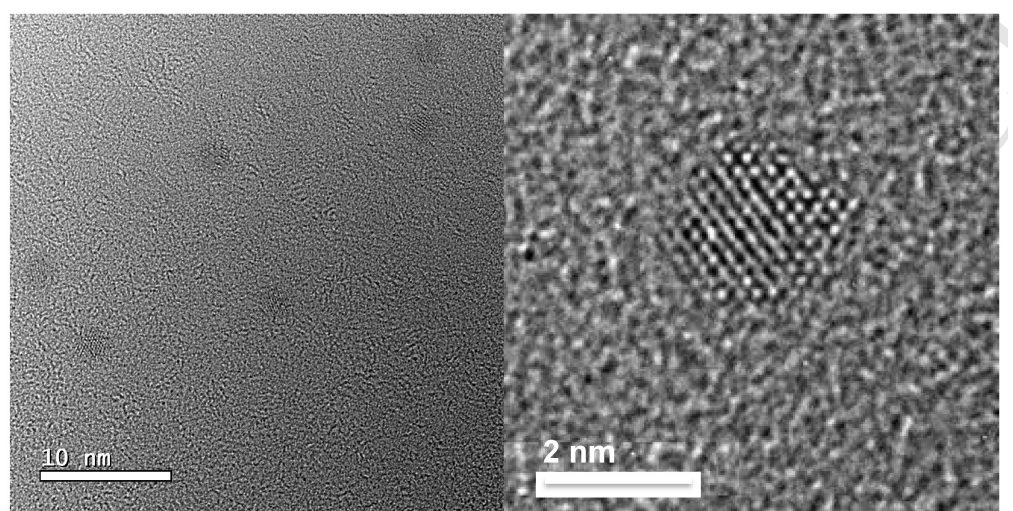

Fig. 6 top: size distributions of a) FeRu, b) CoRu, c) NiRu, d) NiCr, ande) NiFe; bottom: HRTEM images of NiRu nanoparticle, table: mean nanoparticle sizes for ail bimetallic systems before (top line), and after(bottom line) the reductive pretreatment

This size reduction is directly resulting from the transformation from a PBA structure with a large lattice parameter (approximately $10 \mathrm{~A}$ ) to a metallic alloy structure with a smaller lattice parameter. The narrow size distribution found for all the bimetallic systems demonstrates the fine tuning of the reductive pre-treatment we developed, which has the decisive advantage to let well-defined metallic clusters be formed at relatively high temperature whilst the Ostwald ripening is kept within a limited range. A statistical study of the size of the catalyst nanoparticles after SWCNT growth was also carried out by TEM (see Fig. S7). The mean particle size remains stable even after the growth of the nanotubes, with only very small traces of Oswald ripening, showing that the control of the size is maintained throughout the growth process. Examples of AFM images after the reductive pretreatment are provided in Fig. S4, showing a homogeneous layer of catalyst nanoparticles on the $\mathrm{SiO}_{2} / \mathrm{Si}$ substrate.

To better understand the composition of the nanoparticles after reduction, a more detailed STEM-EDX study was carried out for most of the bimetallic systems. As proven by the previously discussed EDX study on the PBA nanoparticles, the starting 
stoichiometry is very close to $1: 1$ for all the precursors presented in this paper. Accounting that the PBA structure consists of altemating metal ions of different nature uniformly bridged by the cyano ligands, and that the particles form a single layer grafted on the substrate surface, we could reasonably expect that after the reductive pre-treatment, the metallic catalyst nanoparticles will generally be nanoalloys with a 1: 1 stoichiometry.

In order to predict more accurately whether the bimetallic nanoparticles can be solid solutions or segregating systems after reduction, we considered the binary phase diagrams for the related bulk systems. The literature is poor on binary phase diagrams at the nanometer scale for the systems studied here. All the bimetallic combinations except for the $\mathrm{NiRu}$ [38] and the $\mathrm{NiCr}$ [39] systems can form solid solutions in bulk and within the temperature range studied here for a wide range of compositions including 1: 1 stoichiometry [40]'[41]. Around $800{ }^{\circ} \mathrm{C}$, the solid solution of the $\mathrm{NiRu}$ and $\mathrm{NiCr}$ systems cannot exceed $8 \%$ of $\mathrm{Ru}$ and $38 \%$ of $\mathrm{Cr}$ in $\mathrm{Ni}$, respectively. We can therefore expect the occurrence of a phase segregation for those two systems, and the formation of a solid solution for the $\mathrm{FeNi}, \mathrm{FeRu}$, and $\mathrm{CoRu}$ systems.

Fig. 7 shows a high angle annular dark field (HAADF) STEM image, elemental maps for the two metallic components, and the relative map obtained by superimposing the two elemental maps, for each of the studied systems. Elemental maps were extracted at energies of $5.32-5.51 \mathrm{keV}$ ( $\mathrm{Cr} \mathrm{Ka}), 6.30-6.50 \mathrm{keV}$ (Fe Ka), 6.82-7.03 keV (Co Ka), 7.37-7.58 keV ( $\mathrm{Ni} \mathrm{Ka}$ ), and 2.49-2.63 keV (Ru La). As expected from the corresponding bulk binary phase diagrams, both metals are present within each particle on the analyzed area, and appear to be intimately mixed in an alloy-like manner for all bimetallic catalysts except $\mathrm{NiCr}$. In this latter case, the particles on the image present a phase segregation: we observe Janus nanoparticles with a Ni-rich part on one hand, and a Cr-rich part on the other. For all other systems, the preparation method results in the formation of bimetallic particles that are presumably solid solutions. We should note that the absence of Cs (present in the PBA precursor structures for all systems but $\mathrm{FeRu}$, discussed earlier) in the catalyst nanoparticles was also confirmed by this STEM-EDX study (see Fig. S6). We can therefore assume that Cs, and $\mathrm{K}$ do not have any influence on the SWCNT growth process. 


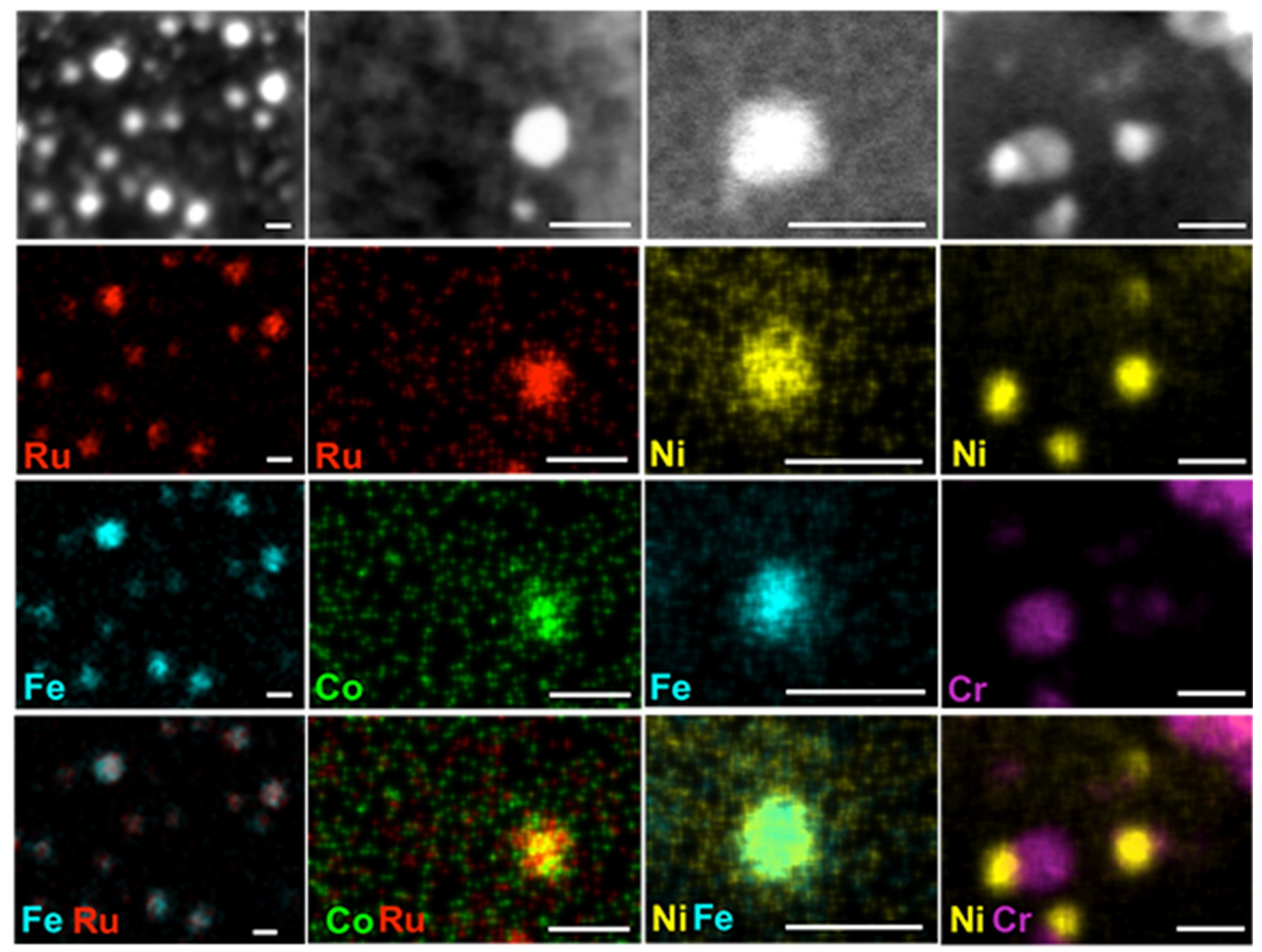

Fig. 7 HAADF-STEM images, and EDX-STEM chemical maps for four systems (FeRu, CoRu, NiFe, and NiCr). For each image the scale bar is $5 \mathrm{~nm}$.

\subsection{SWCNT Growth}

Each ofthe five bimetallic catalyst systems have been tested for SWCNT growth using the d-HFCVD process previously described.[27] The presence of SWCNTs grown on the wafer surfaces in relatively large quantity is sustained through a SEM study and is an indication of the good efficiency of this new catalyst family for the growth of SWCNTs (see Fig. 8a and 8d and Fig. S8).

TEM observations of the nanotubes after their transfer on carbon membranes show the presence of SWCNTs of high crystalline quality and diameters between 1 and $2 \mathrm{~nm}$ (Fig. 8b,d). A substantial amount of PMMA residue from the transfer process was observed on the TEM images. As explained in the experimental section, the rinsing of the PMMA was purposefully only partially done, to ensure that the SWCNTs remain on the TEM grid. We also assume that the organic solvents (mainly acetone) used to rinse off part of the PMMA contribute to this organic residue (see Fig. S9 for TEM image offully rinsed SWCNTs). 

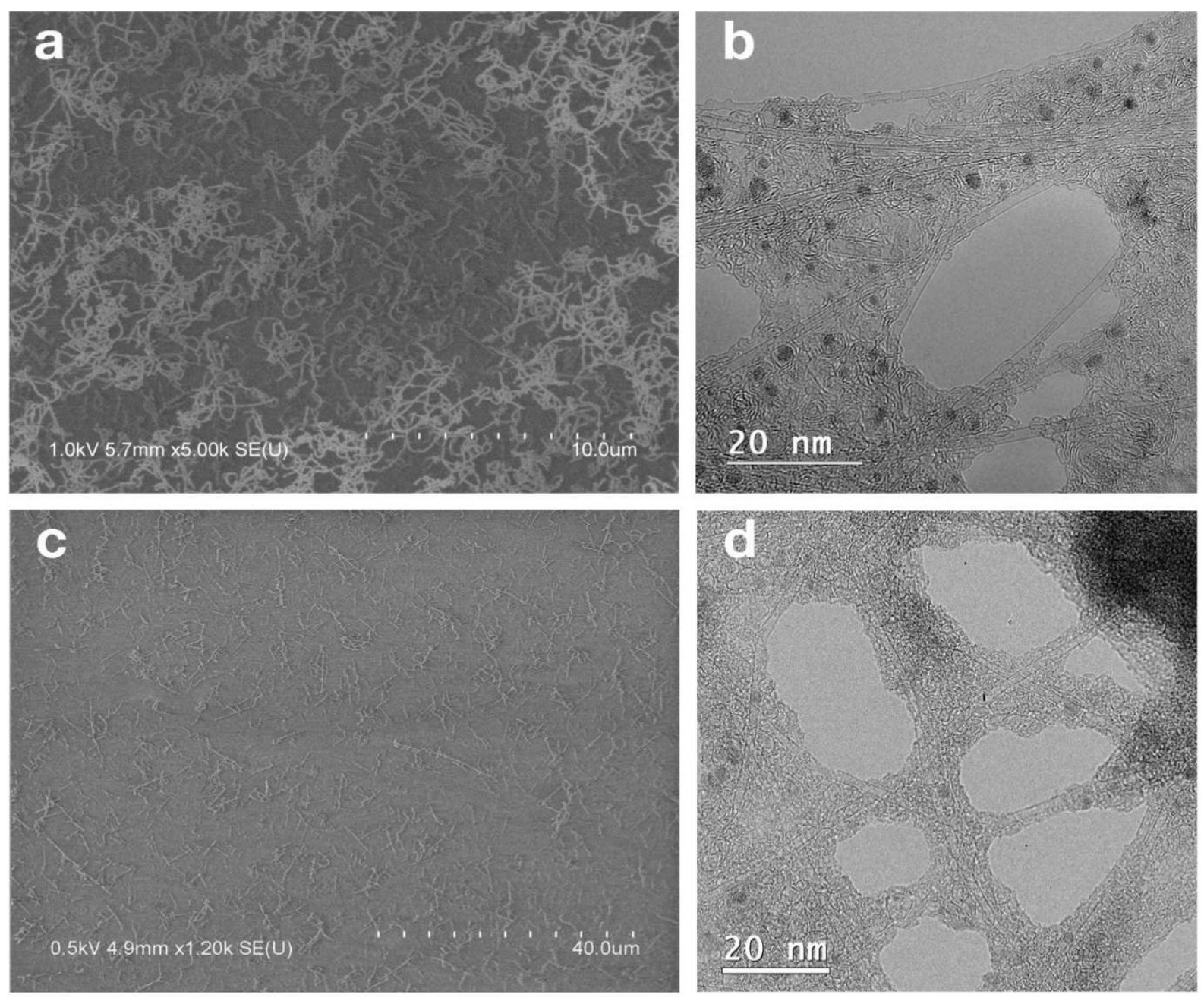

Fig. 8 a) SEM image of SWCNTS grown from CoRu catalysts, b) TEM images of the same SWCNTs transferred onto carbon membrane, c) SEM image of SWCNTs grownfrom NiFe catalysts, and d) TEM image of the same nanotubes traniferred onto carbon membrane

Raman characterizations were also performed in the two spectral ranges representative for the radial breathing mode (RBM) between 100 and $500 \mathrm{~cm}^{-}{ }^{1}$ and respectively between 1200 and $1600 \mathrm{~cm}^{-1}$ for the $\mathrm{sp}^{2}$ carbon D and $\mathrm{G}$ specifie bands [42]. The presence of strong peaks in the RBM range attests the abundance of SWCNTs as seen in Fig. 9a, which shows an example of a Raman mapping using a $633 \mathrm{~nm}$ laser in the case of SWCNTs synthesized from the CoRu catalyst. Analysis of the D and G modes indicates the good crystallinity of the carbon nanotubes (see Fig. S10), with a relatively weak $\mathrm{D}$ band (around $1350 \mathrm{~cm}^{-1}$ ), which always represents less than 10 percent of the intensity of the G-band (around $1590 \mathrm{~cm}^{-1}$ ). We can also underline the fact that, in this spectral range, no amorphous carbon is detected. This demonstrates that the amorphous carbon observed on the TEM images of Fig.8 cannat come from the substrate, and only

originales from the transfer process. Several random mapping regions over the surface of each wafer recorded under four excitation wavelengths $(473,532,633$ and $785 \mathrm{~nm})$ in the RBM spectral range have been analyzed. As a way to compare our five catalyst systems, we calculated the number of SWCNTs detected by Raman with four lasers under one spot (0.6x0.6 f.lill2 approximately). This does not give an absolute measure of the yield, as the 
Raman analysis does not detect ali present SWCNTs, but it is nonetheless an interesting comparison tool. We calculated this nurnber to be 2.1 for the FeRu and CoRu systems, 1.1 for $\mathrm{NiCr}, 0.6$ for $\mathrm{NiRu}$, and 0.3 for $\mathrm{NiFe}$. Our method appears to be more efficient for sorne bimetallic systems than others. However, it is important to underline that we present SWCNT growth for ali systems in the exact same CVD conditions, further optimisation for each system seperately could lead to higher efficiencies.

Those mappings were also analyzed in order to obtain the diameter distributions of the synthesized SWCNTs [43]. We found carbon nanotubes with diameters ranging from 0.7 to $2.6 \mathrm{~nm}$ (see Fig. 9b-f), consistent with the tube diameters observed in TEM. The

diameter selectivity, as determined by Raman, varies from one catalyst system to another. This indicates, considering that the sizes and morphologies of all catalyst systems are quite close, that the chemical nature of the catalyst plays an important role in the SWCNT growth process.
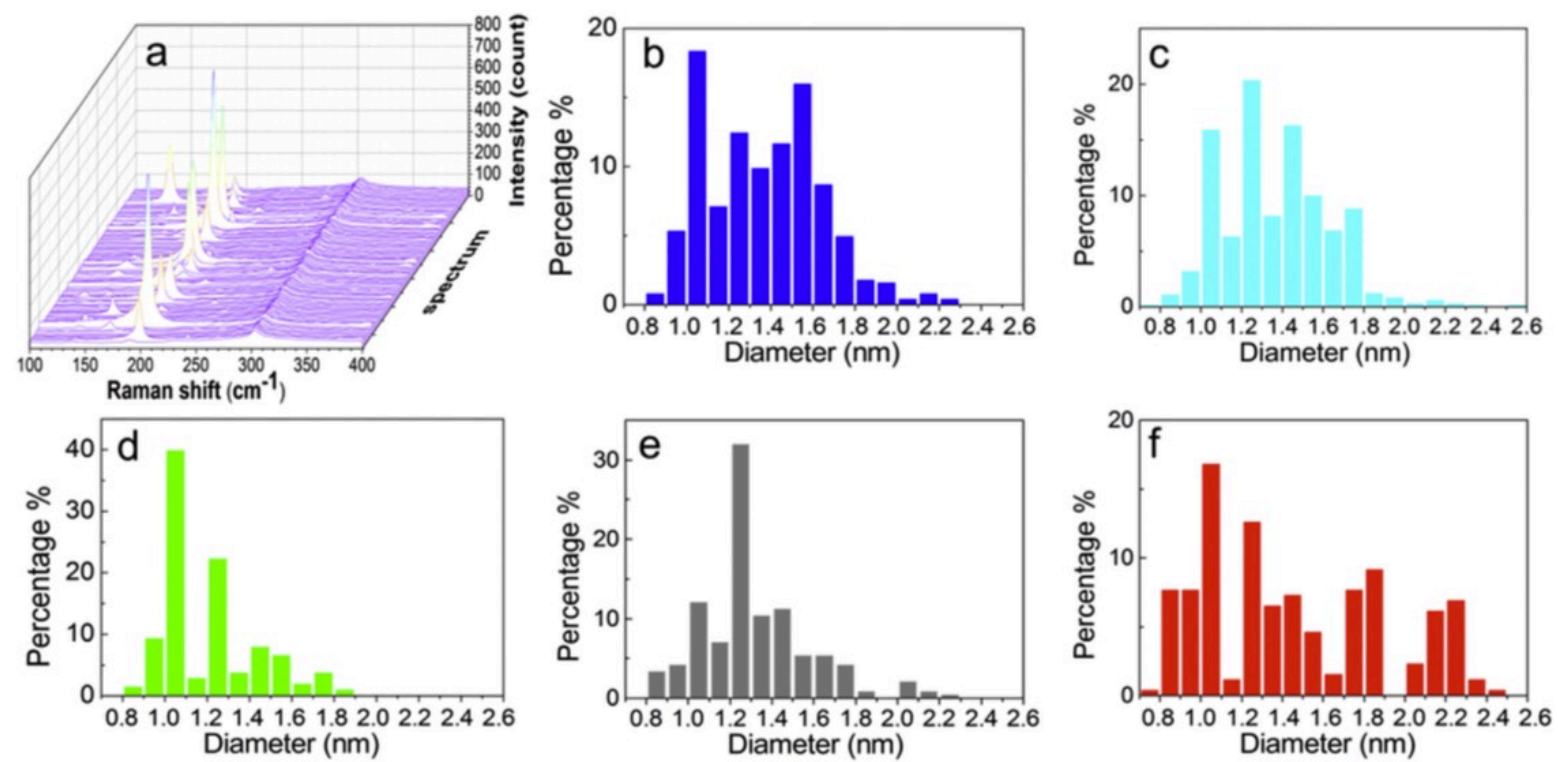

Fig. 9 a) Raman mapping on a $5011 \mathrm{~m}$ by $5011 \mathrm{~m}$ surface in RBM region at $633 \mathrm{nmfor}$ SWCNTs grownfrom CoRu catalyst, and diameter distributions determined by RBM analysis for SWCNTs from b) $\mathrm{FeRu}$, c) $\mathrm{CoRu}$, d) $\mathrm{NiRu}$, e) $\mathrm{NiFe}$, andf) $\mathrm{NiCr}$ catalysts 


\section{Conclusions}

In summary, we have developed a new original, and versatile approach for designing specifie bimetallic catalysts for SWCNT growth from various PBA nanoparticles with narrow size distributions. The structure and the composition of these catalyst precursors have been confirmed by TEM, IR spectroscopy, EDX and XRPD analysis. All data converge to demonstrate that PBAs have been successfully transformed into spherical bimetallic particles. These particles are nanoalloys for all cases inspected by STEM-EDX except for one system, in agreement with bulk binary phase diagrams of the corresponding bimetallic systems. The narrow size distribution of the catalyst nanoparticles is thoroughly determined from statistical analyses of TEM images of nanoparticles assemblies. TEM analyses were further nicely completed by a macroscopic in-situ XPS monitoring of the reductive pre-treatment of the PBA nanoparticles performed for the FeRu system. Finally, we proved that this new family of catalysts allows the growth of SWCNTs with good yield and narrow diameter range as found from both TEM and Raman analyses. Under these conditions, it becomes possible to study the effect of changing one or both of the metal components in the bimetallic alloy catalyst upon the selectivity of the SWCNT growth because the process would be close to identical, except for the nature of the metal in the catalyst. This capability offered by the method presented in this paper paves a large avenue for finding SWCNTs growth selectivity by tuning properties ofthe metal catalyst such as carbon solubility as emphasized in recent studies[44]. It should also be noted that this method is here presented for five bimetallic systems, but can also be easily extended to other bimetallic systems or even multimetallic systems usmg appropriate PBA core-shell pre-catalysts developed previously in our group.[33]

\section{Acknow ledgements}

The research leading to these results has received funding from the European Union Seventh Framework Programme (FP7/2007- 2013) under grant agreement $\mathrm{n}^{\circ} 604472$ (IRENA project), French Research Funding Agency under grant No. ANR-13-BS10-0015-01 (SYNAPSE project), Tempos-NanoTEM and TEMPOS NanoMax. HRSTEM-EDX study was carried out within the MATMECA consortium, supported by the ANR-10-EQPX-37 contract and has benefited from the facilities of the Laboratory MSSMat (UMR CNRS 8579), CentraleSupélec, France. Dr. F. Brisset is acknowledged for the SEM-EDX characterization featured in this paper. Prof. E. Kauppinen, Prof. M. He, Dr. H. Amara and C. Bichara are acknowledged for helpful and stimulating discussions. 


\section{Notes and references}

[1] R. Saito, G. Dresselhaus, M. Dresselahus, Physical Properties of Carbon Nanotubes, 1998.

[2] P. Avouris, Z. Chen, V. Perebeinos, Carbon-based electronics., Nat. Nanotechnol. 2 (2007) 605-15.

[3] P. Bondavalli, P. Legagneux, D. Pribat, Carbon nanotubes based transistors as gas sensors: State of the art and critical review, Sensors Actuators, B Chem. 140 (2009) 304-318.

[4] V. Jourdain, C. Bichara, Current understanding of the growth of carbon nanotubes in catalytic chemical vapour deposition, Carbon N. Y. 58 (2013) 2-39.

[5] C. Lu, J. Liu, Controlling the diameter of carbon nanotubes in chemical vapor deposition method by carbon feeding., J. Phys. Chem. B. 110 (2006) 20254-7.

[6] J. Li, K. Otsuka, X. Zhang, S. Maruyama, J. Liu, Selective synthesis of large diameter, highly conductive and high density single-walled carbon nanotubes by a thiopheneassisted chemical vapor deposition method on transparent substrates, Nanoscale. 8 (2016) 14156-14162.

[7] M. He, H. Jiang, B. Liu, P. V Fedotov, A.I. Chemov, E.D. Obraztsova et al., Chiralselective growth of single-walled carbon nanotubes on lattice-mismatched epitaxial cobalt nanoparticles., Sei. Rep. 3 (2013) 1460.

[8] M. He, A.I. Chemov, P. V Fedotov, E.D. Obraztsova, J. Sainio, E. Rikkinen, et al., Predominant $(6,5)$ single-walled carbon nanotube growth on a copper-promoted iron catalyst., J. Am. Chem. Soc. 132 (2010) 13994--6.

[9] S.M. Bachilo, L. Balzano, J.E. Herrera, F. Pompeo, D.E. Resasco, R.B. Weisman, Narrow $(\mathrm{n}, \mathrm{m})$-distribution of single-walled carbon nanotubes grown using a solid supported catalyst., J. Am. Chem. Soc. 125 (2003) 11186-7.

[10] X. Qin, F. Peng, F. Yang, X. He, H. Huang, D. Luo et al., Growth of semiconducting single-walled carbon nanotubes by using ceria as catalyst supports., Nano Lett. 14 (2014) 512-7.

[11] A.R. Harutyunyan, G. Chen, T.M. Paronyan, E.M. Pigos, O.A. Kuznetsov, K. Hewaparakrama, et al., Preferential growth of single-walled carbon nanotubes with metallic conductivity, Science (80-. ). 326 (2009) 116-120.

[12] Y. Li, S. Peng, D. Mann, J. Cao, R. Tu, K.J. Cho, et al., On the origin of preferential growth of semiconducting single-walled carbon nanotubes., J. Phys. Chem. B. 109 (2005) 6968-71.

[13] M. He, H. Jiang, E.I. Kauppinen, J. Lehtonen, Diameter and chiral angle distribution dependencies on the carbon precursors in surface-grown single-walled carbon nanotubes, Nanoscale. (2012) 7394-7398.

[14] N. Li, X. Wang, F. Ren, G.L. Haller, L.D. Pfefferle, Diameter tuning of single-walled carbon nanotubes with reaction temperature using a $\mathrm{CO}$ monometallic catalyst, J. Phys. Chem. C. 113 (2009) 1007010078.

[15] M. He, H. Amara, H. Jiang, J. Hassinen, C. Bichara, R.H.A. Ras et al., Key roles of carbon solubility in single-walled carbon nanotube nucleation and growth, Nanoscale. 7 (2015) 20284-20289.

[16] W.E. Alvarez, B. Kitiyanan, A. Borgna, D.E. Resasco, Synergism of Co and Mo in the catalytic production of single- wall carbon nanotubes by decomposition of $\mathrm{CO}$, PERGAMON Carbon. 39 (2001) 547-558.

[17] D.E. Resasco, W.E. Alvarez, F. Pompeo, L. Balzano, J.E. Herrera, B. Kitiyanan, et al., A scalable process for production of single-walled carbon nanotubes (SWNTs) by catalytic disproportionation of CO on a solid catalyst, J. Nanoparticle Res. 4 (2002) 
131-136.

[18] X. Li, X. Tu, S. Zaric, K. Welsher, W.S. Seo, W. Zhao, et al., Selective synthesis combined with chemical separation of single-walled carbon nanotubes for chirality selection, J. Am. Chem. Soc. 129 (2007) 15770-1.

[19] K. Cui, A. Kumamoto, R. Xiang, H. An, B. Wang, T. Inoue, et al., Synthesis of subnanometer-diameter vertically aligned single-walled carbon nanotubes with copperanchored cobalt catalysts, Nanoscale. 8 (2016) 1608-1617.

[20] Y. Miyauchi, S. Chiashi, Y. Murakami, Fluorescence spectroscopy of single-walled carbon nanotubes synthesized from alcohol, Chem. Phys. Lett. 387 (2004) 198-203.

[21] M. He, H. Jin, L. Zhang, H. Jiang, T. Yang, H. Cui, F. Fossard et al., Environmental transmission electron microscopy investigations of Pt-Fe203 nanoparticles for nucleating carbon nanotubes, Carbon N. Y. 110 (2016) 243-248.

[22] M. He, L. Zhang, H. Jiang, H. Yang, F. Fossard, H. Cui et al., FeTiO based catalyst for large-chiral-angle single-walled carbon nanotube growth, Carbon N. Y. 107 (2016) 865-871.

[23] M. He, P. V. Fedotov, A. Chemov, E.D. Obraztsova, H. Jiang, N. Wei, et al., Chiralselective growth of single-walled carbon nanotubes on Fe-based catalysts using $\mathrm{CO}$ as carbon source, Carbon N. Y. 108 (2016) 521-528.

[24] F. Yang, X. Wang, D. Zhang, J. Yang, D. Luo, Z. Xu et al., Chirality-specific growth of single-walled carbon nanotubes on solid alloy catalysts., Nature. 510 (2014) 522-4.

[25] H. An, A. Kumamoto, H. Takezaki, S. Ohyama, Y. Qian, T. Inoue, et al., Chirality specifie and spatially uniform synthesis of single-walled carbon nanotubes from a sputtered Co-W bimetallic catalyst, Nanoscale. 8 (2016) 14523-14529.

[26] A. Ludi, H.U. Güdel, Structural chemistry of polynuclear transition metal cyanides, Inorg. Chem. (1973) 1-21.

[27] F.Z. Bouanis, L. Baraton, V. Huc, D. Pribat, C.S. Cojocaru, High-quality single-walled carbon nanotubes synthesis by hot filament CVD on Ru nanoparticle catalyst, Thin Solid Films. 519 (2011) 4594--4597.

[28] F.Z. Bouanis, C.S. Cojocaru, V. Huc, E. Norman, M. Chaigneau, J.-L. Maurice et al., Direct Synthesis and Integration of Individual, Diameter-Controlled Single-Walled Nanotubes (SWNTs), Chem. Mater. 26 (2014) 5074-5082.

[29] D. Brinzei, L. Catala, N. Louvain, G. Rogez, O. Stéphan, A. Gloter et al., Spontaneous stabilization and isolation of dispersible bimetallic coordination nanoparticles of CsxNi[Cr(CN)6]y, J. Mater. Chem. 16 (2006) 2593.

[30] L. Catala, T. Gacoin, J.P. Boilot, É. Rivière, C. Paulsen, E. Lhotel, et al., Cyanidebridged Criii-Nill superparamagnetic nanoparticles, Adv. Mater. 15 (2003) 826-829.

[31] L. Jiao, B. Fan, X. Xian, Z. Wu, J. Zhang, Z. Liu, Creation of Nanostructures with Poly(methyl methacrylate) -Mediated Nanotransfer Printing, J. Am. Chem. Soc. 130 (2008) 12612-12613.

[32] Y. He, D. Li, T. Li, X. Lin, J. Zhang, Y. Wei et al., Metal-film-assisted ultra-clean transfer ofsingle-walled carbon nanotubes, Nano Res. 7 (2014) 981-989.

[33] L. Catala, D. Brinzei, Y. Prado, A. Gloter, O. Stéphan, G. Rogez et al., Core-multishell magnetic coordination nanoparticles: Toward multifunctionality on the nanoscale, Angew. Chemie- Int. Ed. 48 (2009) 183-187.

[34] W.-H. Chiang, M. Sakr, X.P.A. Gao, R.M. Sankaran, Nanoengineering NixFelx Catalysts for Gas-Phase, Selective Synthesis of Semiconducting Single-Walled Carbon Nanotubes, ACS Nano. 3 (2009) 4023-4032.

[35] S.-J. Kyung, M. Voronko, Y.-H. Lee, C.-W. Kim, J.-H. Lee, G.-Y. Yeom, Growth of carbon nanotubes by atmospheric pressure plasma enhanced chemical vapor deposition using NiCr catalyst, Surf. Coatings Technol. 201 (2007) 5378-5382. 
[36] S.J. Kyung, Y.H. Lee, C.W. Kim, J.H. Lee, G.Y. Yeom, Effect ofPretreatment on the Deposition of Carbon Nanotubes by Using Atmospheric-Pressure Plasma-Enhanced Chemical-Vapor Deposition, J. Korean Phys. Soc. 47 (2005) 463-468.

[37] T. Mallah, S. Tricard, F. Charra, Sequential growth at the sub $10 \mathrm{~nm}$ scale of cyanide bridged coordination networks on inorganic surfaces, Dalt. Trans. 42 (2013) 1583515845.

[38] H. Okamoto, Ni-Ru (Nickel-Ruthenium), J. Phase Equilibria Diffus. 30 (2009) 412.

[39] P.E.A. Turchi, L. Kaufman, Z.K. Liu, Modeling ofNi-Cr-Mo based alloys: Part 1-phase stability, Calphad Comput. Coupling Phase Diagrams Thermochem. 30 (2006) 70-87.

[40] G. V. Raynor, V.G. Rivlin, The Fe-Ni (Iron-Nickel) system, Bull. Alloy Phase Diagrams. 2 (1981) 102.

[41] T.B. Massalski, H. Okamoto, P.R. Subramanian, L. Kacprzak, Binary alloy phase diagrams, 2nd Edition, ASM International, 1990.

[42] M. Dresselhaus, G. Dresselhaus, R. Saito, A. Jorio, Raman spectroscopy of carbon nanotubes, Phys. Rep. 409 (2005) 47-99.

[43] A. Jorio, R. Saito, J.H. Hafner, C.M. Lieber, M. Hunter, T. McClure et al., Structural $(\mathrm{n}, \mathrm{m})$ Determination of Isolated Single-Wall Carbon Nanotubes by Resonant Raman Scattering, Phys. Rev. Lett. 86 (2001) 1118-1121.

[44] M. He, Y. Magnin, H. Amara, H. Jiang, H. Cui, F. Fossard et al., Linking growth mode to lengths of single-walled carbon nanotubes, Carbon N. Y. 113 (2017) 231-236. 